\title{
ALGUNS APONTAMENTOS SOBRE A EPISTEMOLOGIA FEMINISTA
}

\author{
NOTES ABOUT THE FEMINIST EPISTEMOLOGY
}

\author{
Amanda Motta Angelo Castro ${ }^{1}$ e Edla Egger ${ }^{2}$
}

Recebido em: 15/04/2011

Aprovado em: 28/04/2012

\begin{abstract}
"Uma epistemologia do Sul assenta em três orientações: aprender que existe o sul; aprender a ir para o Sul; aprender a partir do Sul e com o Sul (SANTOS, 1995).
\end{abstract}

\section{RESUMO}

Este artigo tem como objetivo principal realizar alguns apontamentos sobre a Epistemologia Feminista. Abordaremos aqui ações individuais de mulheres comuns ao longo dos tempos até o movimento coletivo de mulheres nas décadas de $60 \mathrm{e}$ 70. Por que tivemos que buscar uma "alternativa" ao modelo "clássico" e "tradicional" da Epistemologia? Qual a real necessidade e importância de trabalharmos com a Epistemologia Feminista, sobretudo quando realizamos pesquisas sobre mulheres, gênero e feminismo? Aqui buscamos levantar algumas dessas questões e, com isso, acreditamos, em alguma medida, estar contribuindo para os Estudos Feministas e de Gênero, que buscam visibilizar "as margens" nas quais as mulheres estiveram durante séculos de silenciamento (PERROT, 2007).

Palavras-chave: Epistemologia; Feminismo; Gênero; Mulheres.

\section{Introdução}

A necessidade de uma epistemologia que pense a partir das margens, dos/as excluídos/as e dos/as invisibilizados/as não é "privilégio" das mulheres,. Em seu livro, Epistemologias do Sul, Boaventura de Souza Santos (2009) nos aponta a necessidade urgente de o conhecimento sistematizado aprender e reconhecer a existência epistemológica do Sul. Segundo o autor, no Sul, são

\section{ABSTRACT}

This paper aims at providing some pointers on Feminist Epistemology. We will discuss here the individual actions of ordinary women throughout the ages until the collective movement of women in the 60 's and 70 's. Why we had to seek an "alternative" to the "classical" model and "traditional" epistemology? What is the real need and importance of working with the Feminist Epistemology, especially when we conduct research on women, gender and feminism? Here we try to raise some of these issues and we believe in some measure be contributing to Women's Studies and Gender visualizer search "margins" where for centuries women have been muting (PERROT, 2007).

Keywords: Epistemology; Feminism; Gender; Women.

desenvolvidos conhecimentos não reconhecidos "oficialmente". Para Santos (2009), "a epistemologia que conferiu à ciência a exclusividade do conhecimento valido" (SANTOS, 2009, p.11) e essa epistemologia, que valida o conhecimento, "esqueceu" trabalhadores, mulheres, indígena, afrodescendentes, e esses excluídos e excluídas estão, sobretudo, no conjunto de países e regiões submetidos ao colonialismo europeu (SANTOS, 2009).

\footnotetext{
${ }^{1}$ Mestre em Educação. Doutoranda em Educação pela Universidade do Vale do Rio dos Sinos (UNISINOS), Brasil. Bolsista CAPES. E-mail: motta. amanda@terra.com.br.

${ }^{2}$ Mestre em Educação. Doutora em Educação pela EST - Coordenadora do Programa de Pós-Graduação em Educação da Universidade do Vale do Rio dos Sinos (PGEDU/UNISINOS), Brasil. E-mail: edla@unisinos.br.
} 
Nosso artigo caminha na direção da reflexão pertinente de Boaventura sobre as epistemologias desvalorizadas e não reconhecidas pelo conhecimento formal. Entre essas epistemologias está a feminista, que vai pensar a partir do conhecimento produzido pelas mulheres. Aqui não nos propomos criar uma nova epistemologia, mas revisitar a epistemologia feminista que foi pensada e fundamentada a partir do movimento feminista e de intelectuais feministas que compreenderam a necessidade de uma epistemologia "alternativa" ao modelo androcêntrico do conhecimento formal. Neste texto, propomos, ao leitor e a leitora, ir ao Sul e perceber o conhecimento tramado pelas mulheres.

As mulheres foram excluídas da maior parte dos direitos sociais e políticos; seu lugar social, por séculos, foi à esfera privada e não a pública. Logo, estamos nos referindo há séculos de exclusão e silenciamento das mulheres no espaço público e, pensando sobre a pesquisa, cabe aqui uma pergunta: quais serão as consequências disso na pesquisa com mulheres? Segundo Perrot (2007), o pouco registro escrito deixado pelas mulheres ao longo da história, devido à sua exclusão das instituições formais de ensino, é um fator complicador na pesquisa sobre/com mulheres.

Para Gebara (2000), com pouca história escrita pelas mulheres, ao longo do tempo, o conhecimento passou a ser totalmente controlado pelos homens. Sendo assim, a autora afirma que "um conhecimento que despreza a contribuição das mulheres não é apenas um conhecimento limitado e parcial, mas um conhecimento que mantém um caráter de exclusão" (2000, p. 117). Evidentemente, o poder de contar a história e escrevê-la ficou como tarefa dos homens e, aqui, não nos referimos a todos os homens, mas a um padrão normativo androcêntrico. Por consequência, quando discutimos o monopólio do conhecimento pelos homens, referimo-nos a um modelo de homem que, em sua maioria, é branco, heterossexual e tem certo nível de poder. Em vista disso, podemos afirmar que esse monopólio também é excludente para com outros homens. Decorrente dessas exclusões, na história recente, houve um período marcado por movimentos sociais de protesto para que essas desigualdades fossem questionadas, visibilizadas e transformadas.

\section{As margens visibilizadas: os movi- mentos sociais}

Segundo nosso entendimento, foram os movimentos sociais que fizeram com que esse monopólio fosse questionado. Entre os tais, temos: movimento hippie, movimento antirracismo, movimento estudantil, Teologia da Libertação, lutas contra as ditaduras na América Latina, Educação Popular, Revolução Cubana, movimento dos Trabalhadores Sem Terra, Independência de países Africanos e o movimento feminista. Há ícones, até hoje, amados/as e lembrados/as, como: Che Guevara, Nelson Mandela, Rosa Parks, Luther King, Malcon X, John Lennon, Maysa, Leila Diniz, Simone de Beauvoir. As décadas de 1960 e 1970 foram décadas "das margens" pressionando o centro. Durante vinte anos, o mundo viveu movimentos contra a cultura e a ideologia vigente. Com certeza, muitas pessoas que viveram nessas décadas escreveriam com a autoridade da experiência e agregariam outros movimentos e mudanças que tais décadas anunciaram a nós, que não estávamos lá. Nós apenas ouvimos falar e lemos sobre esse tempo e apreciamos a luta, o coletivo, a moda. Hoje desfrutamos de conquistas realizadas pelas pessoas comuns ou não dessa geração.

É no bojo desse momento histórico que surge o movimento feminista, dando origem à epistemologia feminista. Sobre o movimento feminista, entendemos ser pertinente destacar aqui duas questões fundamentais: a primeira é que, ainda hoje, embora erroneamente, muitas pessoas acreditem que todos os direitos fo- 
ram conquistados, superado e que a luta feminista é desnecessária. Nós, as feministas apoiadas pelas tristes estatísticas, sabemos que ainda temos muitas lutas a serem travadas, e conquistas ainda precisam acontecer. Hoje, segundo dados da síntese de indicadores sociais do IBGE de 2008, em todas as posições de trabalho que ocupam, o rendimento médio dos homens é maior que o das mulheres. As mulheres recebem $22 \%$ a menos que os homens ${ }^{3}$, segundo Eggert:

(...) dados fornecidos pelo Ministério do Desenvolvimento, Indústria e Comércio Exterior, organizados juntamente com o Programa do Artesanato Brasileiro (PAB) e do Sistema de Informações Cadastrais do Artesanato Brasileiro (SICAB). Através destes dados constatamos que cerca de $80 \%$ do número total dos artesãos cadastrados são mulheres. Quase 90\% do total moram em zona urbana, bem como realizam suas atividades na própria residência. Sendo que 52\% dos artesãos e das artesãs recebem menos de um salário mínimo nacional, e $42 \%$ recebem entre um a cinco salários. Dificilmente ultrapassam do valor de um salário mínimo. Grande parte do comércio dessa produção é feita na própria residência (49\%), $22 \%$ em feiras, e $14 \%$ em ruas ou praças (EGGERT, 2010, p. 2).

Esses são alguns dos motivos, dentre tantos, que fazem com que os movimentos iniciados nas décadas acima citadas ainda continuem. Destacamos, junto com o movimento feminista, a Educação Popular, pois ambos, até os dias atuais, lutam e acreditam que tais movimentos precisam ser contínuos. Todavia, poderíamos citar os movimentos de igualdade racial que hoje ainda permanecem, porque precisam lutar. Passados quarenta anos após o assassinato de Martin Luther King, eles ainda

${ }_{3}^{3}$ Indicadores Sociais, do Instituto Brasileiro de Geografia e Estatística (IBGE), pesquisa concluída em 2008 e divulgada em 2009. Disponível em: <http://www.ibge.gov.br/home/estatistica/ pesquisas/default. shtm> acessado em 09/10/2009 (INSTITUTO BRASILEIRO DE GEOGRAFIA E ESTATÍSTICA, 2009). têm um sonho ${ }^{4}$. Das décadas de $60 \mathrm{e}$ 70 até os dias atuais, intelectuais e militantes sabem que a igualdade não foi totalmente alcançada. Por isso, tanto o Feminismo quanto a Educação Popular permanecem ativos, tanto na academia como nos movimentos sociais.

A segunda questão é: se ocorreu um movimento feminista nas décadas citadas, isso também ocorreu devido a movimentos "micro", realizados individualizadamente por mulheres que ousaram, ao longo da história, lutar, resistir e transformar. Destacamos aqui quatro dessas mulheres: Safo, na Grécia, em 593 a.C; Olympe de Gouges, na França (1748 - 1793); Nísia Floresta, no Brasil (1810-1885); e Rosa Parks, nos Estados Unidos (1913 - 2005).

\section{Entre o individual e o coletivo}

Safo de Lesbos viveu na Grécia, onde era proibida a educação formal de mulheres, e criou, na ilha de Lesbos, uma escola para mulheres. Invisibilizada pela história, ela entra para os anais de outra forma: pela linguagem. Se pensarmos na origem das palavras safada e lésbica, até hoje pejorativas em nosso vocabulário, temos uma noção de como Safo era vista em sua época (Matos, 2002).

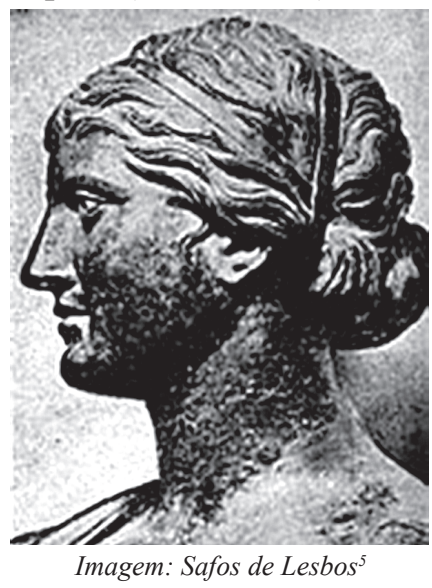

Olimpy de Gouges foi apontada

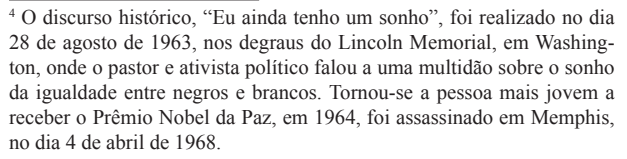

"O discurso histórico, "Eu ainda tenho um sonho", foi realizado no dia 8 de agosto de 1963, nos degraus do Lincoln Memorial, em Washingda igualdade entre negros e brancos. Tornou-se a pessoa mais jovem no dia 4 de abril de 1968 . 
como a primeira pessoa a escrever um texto com linguagem inclusiva. Em 1791, ela escreveu a Declaração dos Direitos da Mulher e da Cidadã e sempre manteve sua célebre frase: "Se a mulher tem o direito de subir ao cadafalso, ela deve ter igualmente o direito de subir à tribuna" (EGGERT, 2006 p 187). Sua luta continuou até o dia em que foi guilhotinada na capital Francesa: 3 de novembro de 1793.

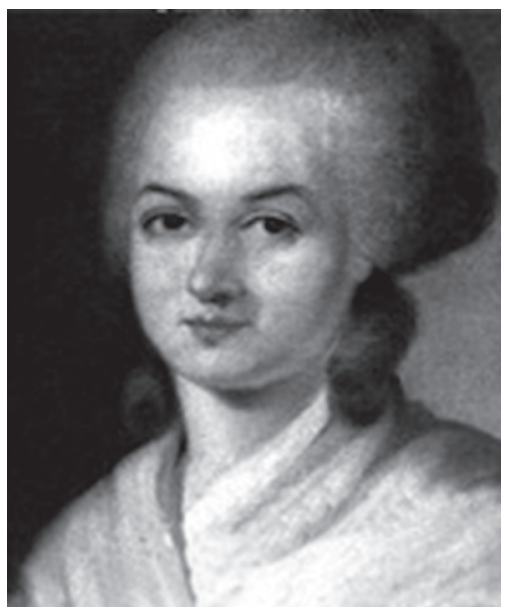

Imagem: Olimpy de Gouges ${ }^{5}$

Nísia Floresta, que, segundo Duarte (1995) e Eggert (2006), é considerada a primeira feminista brasileira, desafiou a legislação assinada por Dom Pedro I, que impedia as mulheres de se matricularem em escolas avançadas. Ela investiu na educação sem distinção entre os sexos, lutou pela educação científica para mulheres e conseguiu a primeira escola exclusiva para meninas, o Colégio Augusto, no Rio de Janeiro, com métodos inovadores. O Colégio de Nísia investia numa educação com competência intelectual para as mulheres. Pioneira em sua época, ela esteve presente na luta pelos direitos da mulher e pela igualdade entre mulheres e homens, sobretudo no campo intelectual (CASTRO, ALBERTON, EGGERT, 2010).

${ }^{5}$ Olympe de Gouges. Fonte $<$ http://www.linternaute.com/femmes/dossier/0704-femmes-histoire/images/gouges.jpg $>$ acessado em ABRI 2009.

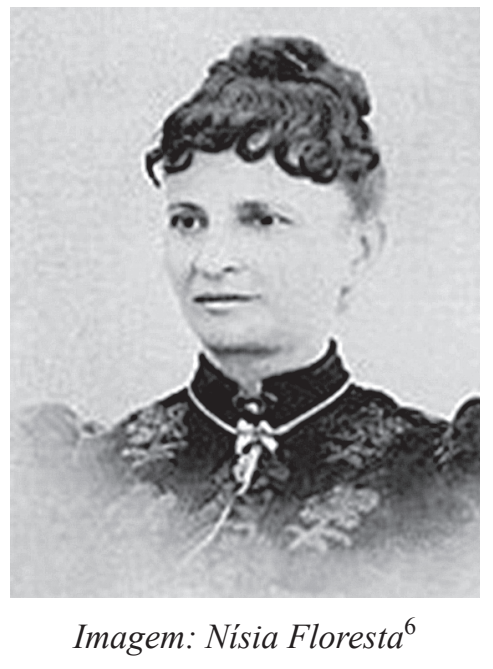

Por fim, mas não menos importante, Rosa Parks ${ }^{7}$, costureira nascida no Alabana e ativista política pelos direitos dos/as negros/as. No dia $1^{\circ}$ de dezembro de 1955, negou-se a dar seu lugar no ônibus a um homem branco, o que se tornou o estopim do boicote aos ônibus no Sul dos Estados Unidos. Rosa encontrou apoio num jovem pastor negro: Martin Luther King, que, posteriormente a esse fato, veio marcar o início da luta antissegregacionista e entrar para os livros de História para sempre.

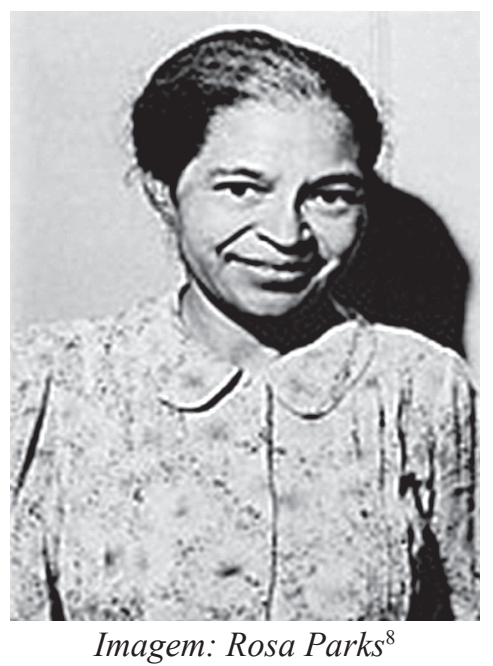

Nísia Floresta. Fonte: <http://www.substantivoplural.com.br/wp-content/uploads $/ 2010 / 05 /$ nisia-floresta.jpg $>$ acessado em ABRI 2010.

${ }^{7}$ Conforme informações obtidas no site oficial do "Rosa Parks Institute" www.rosaparks.org. Acessado em 26 de maio de 2010.

${ }^{8}$ Rosa Parks. Fonte $<$ http://30.media.tumblr.com/tumblr_kxo4qdIcEN1qamvyto1_400.jpg > acessado em NOV 2010. 
Assim, com ações individuais de várias mulheres (incluindo as citadas aqui) ao redor do mundo, durante diferentes tempos e lugares, elas provaram que a história pessoal é parte de uma grande história (EGGERT, 2002). Através delas, podemos chegar ao movimento coletivo no qual ocorre o movimento feminista. Como nos referimos anteriormente, influenciada por esse movimento, surgiu a epistemologia feminista, que vem produzindo conhecimento ao redor do mundo. Segundo Gebara, "o feminismo denuncia a produção de um conhecimento considerado científico, cuja consequência é a exclusão das mulheres e uma cultura marginalizante" (2000, p.115).

\section{Epistemologia: um conhecimento tramado entre o cotidiano e a expe- riência}

A epistemologia tradicional, exercida pelas instituições formais de ensino, busca, em alguma medida, processar e filtrar o conhecimento. Gebara (2008) nos apresenta o argumento de uma epistemologia da vida ordinária, que busca, a partir do cotidiano, da vida das pessoas comuns, mostrar outras formas de conhecimento tecidas no dia-a-dia. Segundo a autora, a epistemologia da vida ordinária é a epistemologia de todos/as nós, de todos/as os/as mortais. Entender e filtrar os conhecimentos ordinários produzidos à margem das instituições formais tem sido, até hoje, uma luta constante para a epistemologia feminista. Eggert (2008) afirma que, por muito tempo, as mulheres foram por elas mesmas, esquecidas e, por consequência, foram esquecidas pela Academia.

Devido às questões por nós levantadas, a pesquisa com mulheres requer algumas abordagens peculiares, para além da epistemologia reflexiva ou científica. Aqui, pensamos e sabemos que não se pode abandonar, de forma alguma, a epistemologia cientifica, entretanto, precisamos de outras alternativas.
A epistemologia feminista tem denunciado e alertado a supergeneralização, apontando que os valores, as experiências, os objetivos e as interpretações dos grupos dominantes são apenas os valores, as experiências, os objetivos e as interpretações desses grupos, não da humanidade como um todo. Sobre isso, Gebara afirma que:

Sem dúvida, o conhecimento produzido por uma elite a serviço dos detentores do poder é mais valorizado do que qualquer outro produzido, por exemplo, por um grupo de catadores de lixo. Não só a questão das classes sociais aparece de forma marcante em todos os processos epistemológicos, mas também a questão da raça, do gênero, das idades, e da orientação sexual. Nossa maneira de expressar nosso conhecimento do mundo é reveladora de nosso lugar social e cultural. E este lugar condiciona nossa confiança e desconfiança, nossa valoração maior ou menos em relação ao que proposto como conhecimento (GEBARA, 2008, p. 32).

Portanto, foi a partir das questões de classe social, gênero, raça, etnia, entre outras, que surgiu uma área da epistemologia dedicada a compreender a forma como o gênero influencia aquelas concepções e práticas, e como têm sistematicamente colocado em desvantagem as mulheres e outros grupos subordinados. Por esse motivo, podemos afirmar que pesquisar mulheres, numa perspectiva feminista, é desafiar uma lógica dominante de um mundo hierárquico $\mathrm{e}$ patriarcal (GEBARA, 2000; 2008).

O olhar epistemológico feminista, tanto ordinário como cientifico, permite reler a história e, sem dúvida, os resultados das inúmeras perspectivas abertas têm sido dos mais criativos e instigantes. A epistemologia feminista aponta, sobretudo, como fonte principal, a experiência. A experiência tecida no cotidiano (PEREIRA, 2009), e, por isso, é invisibilizada (EGGERT, 2006; CAS- 
TRO, BECKER, EGGERT, 2010), e por vezes negligenciada (DEIFET, 2002).

Tanto o feminismo como a Educação Popular apontarão a importância da experiência, pois ambos a consideraram como desencadeadora da produção do conhecimento. Por esse motivo, o conceito de experiência, ainda em construção, tem, para o nosso grupo de pesquisa, um investimento de estudo e debate, segundo Joan Scott (1999):

Precisamos dar conta dos processos históricos que, através dos discursos, posicionam sujeitos que produzem suas experiências. Não são os indivíduos que têm experiências, mas os sujeitos são constituídos através da experiência. A experiência torna-se não a origem de nossa explicação, não a evidencia autorizada que fundamenta o conhecimento, mas sim aquilo que buscamos explicar, aquilo sobre o qual se produz conhecimento (SCOTT, 1999, p 27).

Sabemos que mulheres trazem uma experiência histórica e cultural diferenciada da masculina, uma experiência que, muitas vezes, está às margens. Isso porque, conforme referido anteriormente, essas experiências são do cotidiano ordinário, tecidas em conversas informais, nos espaços privados e nos espaços do lar. Entretanto, nessas margens, encontramos experiências cruciais para a pesquisa com mulheres, o que nos leva a valorizar o conceito de experiência. Sobre isso Eggert (2010) afirma que:

A apreensão da realidade é o retorno ao ateórico, ou seja, o nível da experiência. Nesse sentido, desde a década de setenta, as feministas tinham muita consciência da importância da experiência na luta pela defesa da liberdade e equidade na vida das mulheres. A questão é transformar a experiência do cotidiano e das lutas em teoria não só para traduzi-las, mas para abrangê -las (EGGERT, 2010, p. 7).
Percebemos que trazer o conhecimento ateórico, tecido em espaços do cotidiano, de onde surge a experiência das mulheres, tem sido uma luta feminista desde seu início, sobretudo no que tange a trazê-las como conhecimento. A epistemologia feminista vem rompendo paradigmas estabelecidos, descobrindo e redescobrindo a vida e a produção das mulheres ao longo da história, e de tantas outras que hoje fazem histórias e produzem, como as mulheres de nossa pesquisa. Em alguma medida, tentamos fazer com que suas produções saiam da invisibilidade, que se percebam como atuantes em sua própria história, porque esta não está dada. Como afirma Freire (1999):

Gosto de ser homem (sis), de ser gente, porque sei que a minha passagem pelo mundo não é predeterminada, preestabelecida. Que meu "destino" não é um dado, mas algo que precisa ser feito e de cuja responsabilidade não posso me eximir (FREIRE, 1999, p. 58).

Essa busca por algo que precisa ser construído e que é de nossa responsabilidade requer alguns instrumentos, como afirma Eggert (2009): "buscar instrumentais de outros campos do conhecimento, para alimentar caminhos talvez inusitados; questionar as hierarquias; rever as margens onde as mulheres geralmente se encontram, no ato de produzir conhecimento..." (2009, p. 32).

Para Nancy Pereira (2003 p. 196), "experiência é entendida como uma operação interna - expressão do ser ou da consciência - que projeta uma subjetividade na forma de identidade essencial, de caráter universal, acessível a todos/as". Portanto, a experiência é desenvolvida na vida cotidiana de mulheres, é parte da subjetividade de cada um/uma, e é essa experiência que será base para a epistemologia feminista. $\mathrm{Na}$ visão de Deifelt (2002), podemos atribuir a experiência como base, pois o conhecimento feminista é forjado, dentre outros elementos, no bojo da experiên- 
cia, uma vez que esta produz conhecimento. Evidentemente, trata-se de um conhecimento marginalizado durante séculos, pois o conhecimento das mulheres, devido a sua exclusão do mundo público, foi tecido em espaços privados, logo, espaços tidos como óbvios (EGGERT, 2002) e, consequentemente, invisíveis, como o cotidiano artesanal e doméstico, o espaço privado.

\section{Considerações finais}

O movimento proposto por Santos (2009) de irmos ao Sul e aprendermos com e a partir do Sul, sem dúvida, leva-nos a perceber a diversidade de conhecimento produzido nas "margens". Certamente, os movimentos sociais nas décadas de 60 e 70 foram determinantes para o deslocamento de irmos ao Sul, e para que as margens fossem visibilizadas. A partir desses movimentos, o feminismo tem produzido uma crítica contundente ao modo androcêntrico de produção do conhecimento. Além dessa crítica, tal movimento tem buscado funcionar num alternativo de operação e articulação na esfera do conhecimento, pois faz (re)leituras e novas leituras sabendo que a nossa construção como mulheres passa pelas nossas próprias histórias, que são marcadas pela diversidade. São essas experiências do nosso cotidiano que nos permitem realizar nossa "leitura de mundo", conforme nos ensina Paulo Freire (2006), e, por meio dessa leitura, há novas descobertas, novas mulheres silenciadas através dos séculos, novos processos que propomos visibilizar.

A busca pela valorização das epistemologias do Sul é desafiadora, e acreditamos serem inegáveis as conquistas das mulheres no campo científico, nos poucos anos de epistemologia feminista. Para João Nunes (2009), a critica feminista e a busca pelo reconhecimento da epistemologia Feminista é essencial para o conhecimento cientifico pois a epistemologia feminista trás as distorções masculinas produzidas por diferentes disciplinas, tais como Biologia, Filosofia, História, Medicina e a Ciências Sociais'.

Acreditamos que nossa pesquisa corrobora junto aos trabalhos de muitas outras feministas - tanto nos movimentos sociais como na academia que buscam construir novos caminhos de luta, justiça, respeito, sororidade ${ }^{10}$ e igualdade entre os sexos, pois, assim como os movimentos sociais, a pesquisa é, sem dúvida, uma forma importante de nos descolarmos ao Sul.

\section{Referências}

CASTRO, Amanda Motta Angelo; ALBERTON, M. ; EGGERT, Edla . Nísia Floresta a mulher que ousou desafiar sua época: Feminismo e Educação. In: VIII Congresso Iberoamericano de $\mathrm{Ci}$ ência, Tecnologia e Gênero, 2010, Curitiba. Anais do VIII Congresso Iberoamericano de Ciência, Tecnologia e Gênero. Curitiba: UFTPR, 2010.

CASTRO, Amanda Motta Angelo; BECKER, Márcia. Regina. ; EGGERT, Edla. Técnica e Arte: Trabalho artesanal produzido por mulheres e sua (in)visibilidade social. In: XI Simpósio Internacional IHU: O (des)governo biopolítico da vida humana, 2010, São Leopoldo: IHU, 2010.

DEIFET, Vanda. O corpo e o cosmo. In: TIBIRI, Macia, MENEZES, Magali e EGGERT, Elda. As mulheres e a filosofia. São Leopoldo, UNISINOS, 2002.

DUARTE, Constância Lima. Nísia Floresta: Vida e Obra. Natal: Ufrn, Editora universitária, 1995.

\footnotetext{
"No seu artigo intitulado "O Resgate da Epistemologia", João Nunes aponta importantes estudos realizados por feministas, e como esses estudos influenciaram a mudança do padrão da "normatividade androcêntrica". ${ }^{10}$ Sororidade, palavra resgatada pela Teologia Feminista que significa "ir-
} mãs". Conforme o Dicionário de teologia feminista Vozes, 1999. 
EGGERT, Edla. Narrativas: uma filosofia a partir da experiência das mulheres? In: TIBIRI, Macia, MENEZES, Magali e EGGERT, Elda. As mulheres e a filosofia. São Leopoldo, UNISINOS, 2002.

EGGERT, Edla. A graça do mundo do lado de baixo do equador. In. PEREIRA, Nancy; EGGERT,Edla; MUSSKOPF, André S. A graça do mundo transforma deus. Porto Alegre : Ed. Metodista, 2006.

Trabalho Manual e debate temático: Tramando Conhecimentos na simultaneidade. IN NEUENFELDT, Eliane; BERGSCH, Karen; PARLOW, Mara (Org.). In: Epistemologia, violência, sexualidade: olhares do II Congresso Latino-Americano de Gênero e Religião. São Leopoldo: Sinodal, 2008.

Narrar Processos: Tramas da violência doméstica e possibilidades para a educação. Florianópolis: Editora Mulheres, 2009.

. Trabalho precário x profissionalização de tecelãs: um desafio para a formação educacional no campo do artesanato gaúcho. In: Anais do VIII Congresso Ibero-americano de Ciência, Tecnologia e Gênero. Curitiba: UFTPR, 2010.

FREIRE, Paulo. Pedagogia da autonomia: saberes necessários à prática educativa. 25.ed. São Paulo: Paz e Terra, 1999.

Pedagogia do Oprimido. 45.ed. Rio de Janeiro: Paz e Terra, 2006 GEBARA, Ivone. Rompendo o Silêncio: Uma fenomenologia feminista do mal. São Paulo, Vozes, 2000.

GEBARA. Ivone. As epistemologias teológicas e suas consequências. In: NEUENFELDT, Eliane; BERGSCH, Ka- ren; PARLOW, Mara (Org.). Epistemologia, violência, sexualidade: olhares do II Congresso Latino-Americano de Gênero e Religião. São Leopoldo: Sinodal, 2008.

MATOS, Olgária. Benjamin e o feminino: um nome, o nome. In: TIBIRI, Macia, MENEZES, Magali e EGGERT, Elda. As mulheres e a filosofia. São Leopoldo, UNISINOS, 2002.

NUNES, João Arriscado. O Resgate da Epistemologia. In: SANTOS, Boaventura de Souza; MENESES, Maria Paula. Epistemologias do Sul. Coimbra: CES, 2009.

PEREIRA, Nancy Cardoso. Fragmentos e Cacos de Experiêncial Relações sociais de poder e gênero na teologia wesleyana. In: Revista Caminhando, vol. 8, n. 2, 2003.

O papel é paciente, a história não é: cotidiano sagrado, educação e diversidade religiosa no Brasil. In: OLIVEIRA, Lilian, CECCHETTI, Elcio, CESARO, Rosa Assunta de.(Org.). Cultura e Diversidade Religiosa na América Latina Pesquisas e Perspectivas Pedagógicas. Blunemau: Edifurb, 2009.

PERROT, Michelle. Minha historia sobre as mulheres. São Paulo: Contexto, 2007.

SANTOS, Boaventura de Souza. Toward a New Commn Sense: Law, Science and politics in the paradigmatic Transition. Nova Iorque: Routledge, 1995.

SANTOS, Boaventura de Souza; MENESES, Maria Paula. Epistemologias do Sul. Coimbra: CES, 2009.

SCOTT, Joan. Experiência. In: SILVA, Alcione (org). Falas de gênero: teorias, análises, leituras. Florianópolis: Editora das mulheres, 1999. 